\title{
Performance status is the most powerful risk factor for early death among patients with advanced soft tissue sarcoma
}

\author{
The European Organisation for Research and Treatment of Cancer - Soft Tissue \\ and Bone Sarcoma Group (STBSG) and French Sarcoma Group (FSG) study
}

\section{N Penel ${ }^{*, 1,2}$, MV Glabbeke ${ }^{2}$, S Mathoulin-Pelissier ${ }^{3}$, I Judson $^{4}$, S Sleijfer ${ }^{5}$, B Bui ${ }^{6}$, P Schoffski ${ }^{7}$, M Ouali ${ }^{2}$, S Marreaud ${ }^{2}$, V Brouste $^{3}$, A Duhamel $^{8}$, P Hohenberger' and J-Y Blay $^{10}$}

'Department of General Oncology, Centre Oscar Lambret, Regional Comprehensive Cancer Centre, 3, rue F Combemale, 59020, Lille, France; ${ }^{2}$ European Organisation for Research and Treatment of Cancer, Brussels, Belgium; ' Department of Clinical Epidemiology and Clinical Research, Institut Bergonié, Regional Comprehensive Cancer Centre, Bordeaux, France; ${ }^{4}$ Sarcoma Unit, Royal Marsden Hospital, London, UK; ${ }^{5}$ Department of Medical Oncology, Erasmus Cancer Center, Rotterdam, The Netherlands; ${ }^{6}$ Department of Medical Oncology, Institut Bergonié, Regional Comprehensive Cancer Centre, Bordeaux, France; ${ }^{7}$ Department of General Medical Oncology, Leuven Cancer Center, Leuven, Belgium; ${ }^{8}$ Public Health Unit (EA 2694: Epidemiology and Modelization of Chronic Illness), Lille University, Lille, France; ${ }^{9}$ Division of Surgical Oncology and Thoracic Surgery, Department of Surgery, Medical Faculty Mannheim, University of Heidelberg, Mannheim, Germany; ${ }^{10}$ Léon Bérard Comprehensive Cancer Centre, University Claude Bernard Lyon I, Lyon, France

BACKGROUND: We investigated prognostic factors (PFs) for 90-day mortality in a large cohort of advanced/metastatic soft tissue sarcoma (STS) patients treated with first-line chemotherapy.

METHODS: The PFs were identified by both logistic regression analysis and probability tree analysis in patients captured in the Soft Tissue and Bone Sarcoma Group (STBSG) database (3002 patients). Scores derived from the logistic regression analysis and algorithms derived from probability tree analysis were subsequently validated in an independent study cohort from the French Sarcoma Group (FSG) database (404 patients).

RESULTS: The 90-day mortality rate was 8.6 and $4.5 \%$ in both cohorts. The logistic regression analysis retained performance status (PS; odds ratio $(O R)=3.83$ if $P S=1, O R=12.00$ if $P S \geqslant 2)$, presence of liver metastasis $(O R=2.37)$ and rare site metastasis $(\mathrm{OR}=2.00)$ as PFs for early death. The CHAID analysis retained PS as a major discriminator followed by histological grade (only for patients with PS $\geqslant 2$ ). In both models, PS was the most powerful PF for 90-day mortality.

CONCLUSION: Performance status has to be taken into account in the design of further clinical trials and is one of the most important parameters to guide patient management. For those patients with poor PS, expected benefits from therapy should be weighed up carefully against the anticipated toxicities.

British Journal of Cancer (201 I) I 04, I544-1550. doi:I0.1038/bjc.201 I.I36 www.bjcancer.com

Published online 19 April 2011

(C) 201 I Cancer Research UK

Keywords: soft tissue sarcoma; early death; prediction

Soft tissue sarcomas (STSs) account for approximately 1 to $2 \%$ of all adult cancers. Although local control can be obtained through the use of surgery plus radiotherapy, up to $50 \%$ of patients will recur at distant sites (Clark et al, 2005). At the metastatic stage, palliative chemotherapy can be considered as a reasonable option in the majority of cases. Both ifosfamide and doxorubicin are the best single agents with activity in the treatment of STS. In general, the toxicities are manageable but real, thereby making treatment difficult (Sleijfer et al, 2005; Benjamin 1987). However, most if not

*Correspondence: Dr N Penel; E-mail: n-penel@o-lambret.fr

Presented in part in the 16th annual meeting of the Connective Tissue Oncology Society, Paris, I1-13 November 2010.

Received 30 November 2010; revised 22 March 2011; accepted 27 March 201 I; published online 19 April 201। all patients will ultimately relapse and die of their disease. The median overall survival (OS) is actually $\sim 12$ months and the median time to progression is $\sim 3$ months. Regarding these facts, three options could be considered for the treatment of patients with advanced/metastatic STS: (1) the combination of doxorubicin and ifosfamide if resection of metastasis looks feasible or in the case of symptomatic patients with rapidly progressing tumours (2) single-agent chemotherapy and (3) exclusive best supportive care (Blay et al, 2003; Benjamin 1987). In the everyday practice, many factors are integrated in the decision-making process: general condition of patient, underlying co-morbidities, medical history, resectability of metastasis, patient choice and knowledge of prognostic factors (PFs).

One of the most important factors that should be taken into account is the risk that a patient will die early after initiation of treatment. Particularly in patients with a high risk of dying early, it 
is likely that best supportive care should be preferred over systemic therapy with its accompanying toxicities.

In addition to patient care, insight into factors associated with early death after initiation of treatment is crucial for the design of studies, as the lack of reliable guidance for the life expectancy prediction is likely to introduce some biases in these clinical studies. Moreover, the known PFs for outcome have to be taken into account in the design of clinical trials, for example, as stratification factors at entry for randomised clinical trials (Simon and Altman, 1994).

The literature shows that life expectancy is most often overestimated, which frequently results in overtreatment (Maltoni et al, 1994; Christakis and Lemont, 2000; Penel et al, 2008; Clément-Duchêne et al, 2010). For example, despite the fact that a life expectancy of $<3$ months is an exclusion criterion for all phase I studies, without reliable guidance, $\sim 20-30 \%$ of patients enroled in phase 1 trials in expert centres died within the first 90 days (Arkenau et al, 2008, 2009; Penel et al, 2008). Despite the high need for models establishing the risk for early death and a large body of literature on prognostic models for cancer patients, only few of these models are suitable for daily decision making. Before implementation in clinical practice, such prognostic models need to be identified and subsequently validated in independent series. Additionally, such models should be robust and simple, in order to be easily applied in daily practice.

Regarding the severity of advanced STS and the limited therapeutic options, we carried out a retrospective exploratory analysis to (1) develop prognostic models for early death in such population and (2) then validate the models in an independent data set. For the purpose of this study, two complementary approaches were used for the development of the models (scoring system derived from logistic regression analysis and algorithm derived from decision-tree analysis). The models were developed with the Soft Tissue and Bone Sarcoma Group (STBSG) data set and subsequently validated with the French Sarcoma Group (FSG) data set.

\section{MATERIALS AND METHODS}

\section{Data sets}

We used two data sets. The first one was formed by the STBSG and includes patients treated with single agents and combination regimens as first-line treatments between January 1976 and October 2001. The second one had been built by the FSG and includes patients treated with combination regimen (MAID and intensified-MAID) between January 1994 and October 2008 (Fayette et al, 2009; Bui et al, 2009).

\section{Primary end point}

The primary end point was 90-day mortality (early death). This threshold is believed to be relevant in decision making for advanced cancer patients in whom the choice of whether to treat with chemotherapy or best supportive care need to be discussed (Sessa et al, 1996; Geraci et al, 2006; Kelly et al, 2007; Penel et al, 2009).

\section{Development of the models}

The development of these models used the STBSG database. The potential PFs were: gender, age, performance status (WHO-PS), histological subtypes (angiosarcoma, fibrosarcoma, leiomyosarcoma, malignant histiocytofibroma, malignant peripheral sheath nerve tumour, rhabdomyosarcoma, synovial sarcoma, unclassified STS and unknown subtype and a group containing the remaining rare subtypes), histological grade, tumour location (abdominal, breast, gynaecological, head and neck, lower limbs, skin, trunk upper limbs, visceral, other locations and unknown), time interval since initial diagnosis of STS and start of systemic therapy, presence of lung metastasis, presence of liver metastasis, presence of bone metastasis and presence of other metastases. Two continuous variables (age and time interval since initial diagnosis of STS) were recorded according to the observed quartiles. All these items were collected in both databases.

Two complementary approaches of logistic regression analysis and classification analysis (CHAID) (Melchior et al, 2001; Barton et al, 2005; Chan et al, 2006; Ambalavanan et al, 2006; Courville et al, 2009) were used for development of the prognostic models (scoring system and decision tree, respectively).

Separate logistic regression analysis with stepwise selection of variables (at $P<0.05$ ) identified variables in the entire STBSG cohort associated with early death. The odds ratios (ORs) from the logistic regression model were converted into points by dividing by the smallest OR for any given other OR. Next, an overall score was assigned to each patient by summing the points they received for each of the PFs.

In the current study, CHAID was used as a complementary method; this technique uses a systematic algorithm to detect the stronger association between potential PFs (named 'splitter') and the outcome variable (e.g., early death). Step by step, the CHAID algorithm recursively partitions data into mutually exclusive, exhaustive subsets that are maximally different in the dependent variable (e.g., early death), as assessed with the use of Bonferroniadjusted $\chi^{2}$ statistics. The CHAID algorithm consisted, herein, in three successive actions: (1) merge the subgroups with similar occurrence of target variable $\left(\alpha_{\text {merge }}=0.01\right)$, (2) split the subgroups using the best PF $\left(\alpha_{\text {splitt }}=0.01\right)$ and (3) terminate the tree when the observed number of early death was $\sim 30$ (Melchior et al, 2001; Barton et al, 2005; Chan et al, 2006; Ambalavanan et al, 2006; Courville et al, 2009).

Furthermore, the prognostic accuracy (and its 95\% confidence intervals (95\% CIs)) was tabulated for both models (scoring system and decision-tree analysis) using a classical $2 \times 2$ table. The optimal threshold for each prognostic model was established using classical receiver operating characteristics analysis to maximise both sensitivity and specificity (Linden 2006). The accuracy is basically the rate of well-classified patients.

\section{Validation and head-to-head comparison of both models}

Both models were applied to the independent data set (FSG database). The score was calculated for each patient according to the observed presence of PFs (a patient with any missing source variable was given a missing value of score). The entire population was split according to the proposed CHAID algorithm. Performance of both models had been established using area under receiver operator curve and accuracy as previously specified.

\section{RESULTS}

\section{Patient characteristics}

The main patient characteristics are depicted in Table 1. The STBSG cohort included 3002 patients; 2898 (96.5\%) of them were assessable for the early death rate. The rate of early death was 251 out of 2898 (8.6\% (95\% CI: 7.6-9.6)). In this cohort, the median OS was 348 days. Out of the 404 patients from the FSG cohort, 399 $(98.7 \%)$ were assessable for the early death rate. The rate of early death was 18 out of $399(4.5 \%(2.4-6.5))$. The median OS of this cohort was 788 days.

\section{Development of the scoring system}

The following parameters were associated with the risk of early death in univariate analysis: age $\geqslant 60(\mathrm{OR}=1.77, P=0.003)$, 
Table I The characteristics of patients in both cohorts

\begin{tabular}{|c|c|c|c|}
\hline \multicolumn{2}{|c|}{ Categorical variables } & \multirow{2}{*}{$\begin{array}{c}\text { STBSG } \\
\text { Cases (\%) }\end{array}$} & \multirow{2}{*}{$\begin{array}{c}\text { FSG } \\
\text { Cases (\%) }\end{array}$} \\
\hline Parameters & Categories & & \\
\hline Gender & $\begin{array}{l}\text { Unknown } \\
\text { Men } \\
\text { Women }\end{array}$ & $\begin{array}{r}78(2.6) \\
1464(48.8) \\
1460(48.6)\end{array}$ & $\begin{array}{c}0(0) \\
192(47.6) \\
211(52.4)\end{array}$ \\
\hline Performance status & $\begin{array}{l}\text { Unknown } \\
0 \\
1 \\
2 \\
3\end{array}$ & $\begin{array}{c}\mid 40(4.7) \\
|20|(40.0) \\
|36|(45.3) \\
295(9.8) \\
5(0.2)\end{array}$ & $\begin{array}{c}49(12.2) \\
166(41.2) \\
157(39.0) \\
31(7.7) \\
0(0)\end{array}$ \\
\hline Interval & $\begin{array}{l}\text { Unknown } \\
0-60 \text { days } \\
61-180 \text { days } \\
181-540 \text { days } \\
>540 \text { days }\end{array}$ & $\begin{array}{l}243(8.1) \\
841(28.0) \\
473(15.8) \\
723(24.1) \\
722(24.1)\end{array}$ & $\begin{aligned} 50 & (12.3) \\
274 & (67.9) \\
0 & (0) \\
0 & (0) \\
80 & (19.8)\end{aligned}$ \\
\hline Histological subtypes & $\begin{array}{l}\text { Unknown } \\
\text { Angiosarcoma } \\
\text { Fibrosarcoma } \\
\text { Leiomyosarcoma } \\
\text { Liposarcoma } \\
\text { MHF } \\
\text { MPNST } \\
\text { Other } \\
\text { Rhabdomyosarcoma } \\
\text { Synovial sarcoma } \\
\text { Unclassified }\end{array}$ & $\begin{array}{l}177(5.9) \\
120(4.0) \\
178(5.9) \\
907(30.2) \\
260(8.7) \\
303(10.1) \\
144(4.8) \\
292(9.7) \\
104(3.5) \\
249(8.3) \\
268(8.9)\end{array}$ & $\begin{aligned} & 0(0) \\
& 17(4.2) \\
& 8(2.0) \\
& 108(26.8) \\
& 44(10.9) \\
& 20(5.0) \\
& 16(4.0) \\
& 68(16.9) \\
& 22(5.5) \\
& 34(8.4) \\
& 66(16.4)\end{aligned}$ \\
\hline Grade & $\begin{array}{l}\text { Unknown } \\
\text { I } \\
\text { II } \\
\text { III } \\
\text { Not applicable }\end{array}$ & $\begin{array}{l}\text { II } 22(37.4) \\
267(8.9) \\
707(23.6) \\
906(30.2) \\
0(0)\end{array}$ & $\begin{array}{r}25(6.2) \\
20(5.0) \\
107(26.6) \\
177(43.0) \\
74(18.4)\end{array}$ \\
\hline Location & $\begin{array}{l}\text { Unknown } \\
\text { Abdominal } \\
\text { Breast } \\
\text { Gynaecological } \\
\text { Head and neck } \\
\text { Lower limbs } \\
\text { Other } \\
\text { Skin } \\
\text { Trunk } \\
\text { Upper limbs } \\
\text { Visceral }\end{array}$ & $\begin{aligned} & 1068(35.6) \\
& 409(13.6) \\
& 23(0.8) \\
& 281(9.4) \\
& 78(2.6) \\
& 507(16.9) \\
& 18(0.6) \\
& 15(0.5) \\
& 231(7.7) \\
& 170(5.7) \\
& 202(6.7)\end{aligned}$ & $\begin{aligned} & 1(0.2) \\
& 67(16.6) \\
& 0(0) \\
& 56(13.9) \\
& 18(4.5) \\
& 138(34.2) \\
& 8(2.0) \\
& 2(0.5) \\
& 23(6.9) \\
& 31(7.7) \\
& 54(13.4)\end{aligned}$ \\
\hline Lung met. & $\begin{array}{l}\text { Unknown } \\
\text { No } \\
\text { Yes }\end{array}$ & $\begin{array}{c}134(4.5) \\
1280(42.6) \\
1588(52.9)\end{array}$ & $\begin{array}{r}125(31.0) \\
86(21.3) \\
192(47.6)\end{array}$ \\
\hline Liver met. & $\begin{array}{l}\text { Unknown } \\
\text { No } \\
\text { Yes }\end{array}$ & $\begin{aligned} 270 & (9.0) \\
2211 & (73.7) \\
521 & (17.4)\end{aligned}$ & $\begin{array}{r}125(31.0) \\
230(57.1) \\
48(11.9)\end{array}$ \\
\hline Bone met. & $\begin{array}{l}\text { Unknown } \\
\text { No } \\
\text { Yes }\end{array}$ & $\begin{array}{r}602(20.1) \\
2122(70.7) \\
278(9.3)\end{array}$ & $\begin{array}{c}126(31.3) \\
240(59.6) \\
37(9.2)\end{array}$ \\
\hline Other met. & $\begin{array}{l}\text { Unknown } \\
\text { No } \\
\text { Yes }\end{array}$ & $\begin{array}{r}639(21.3) \\
1329(44.3) \\
1034(34.4)\end{array}$ & $\begin{array}{c}126(31.3) \\
240(59.6) \\
37(9.2)\end{array}$ \\
\hline Previous chemotherapy & $\begin{array}{l}\text { Unknown } \\
\text { No } \\
\text { Yes }\end{array}$ & $\begin{array}{c}129(4.3) \\
2825(94.1) \\
48(1.6)\end{array}$ & $\begin{aligned} 0 & (0) \\
404 & (100) \\
0 & (0)\end{aligned}$ \\
\hline
\end{tabular}

Abbreviations: STBSG = Soft Tissue and Bone Sarcoma Group; FSG = French Sarcoma Group; $\mathrm{MHF}=$ malignant histiocytofibroma; MPNST = malignant peripheral nerve sheath tumour; met. $=$ metastasis

$\mathrm{PS}=1 \quad(\mathrm{OR}=3.04, P<0.0001), \mathrm{PS} \geqslant 2(\mathrm{OR}=10.00, P<0.0001)$, time interval since the initial diagnosis of sarcoma $\geqslant 540$ days $(\mathrm{OR}=0.41, P<0.0001)$, presence of liver metastasis $(\mathrm{OR}=2.37$,
$P=0.0041)$ and presence of other metastases $(\mathrm{OR}=2.00$, $P=0.0061$; Table 2). The final logistic regression analysis retained the following PFs for early deaths: PS $=1 \quad(P<0.0001)$, PS $\geqslant 2$ $(P<0.0001)$, presence of liver $(P=0.0014)$ or other metastases $(P=0.0055)$. For the attribution of points in the scoring system, each adjusted OR was divided by the smallest one, which appeared to be the presence of metastases other than lung, bone and liver with an OR of 2.0. Thus, PS $=1$ then gave 2 points $(3.83 / 2.00)$, PS $\geqslant 2$ gave 6 points $(12.00 / 2.00)$, presence of liver metastasis gave 1 point $(2.37 / 2.00)$ and presence of other metastases also gave 1 point $(2.00 / 2.00)$. As a result, the sum of points ranged from 0 to 8 and the risk of early death from 3 to $40 \%$ (Table 3 ). The area under receiver operator curve was $0.69(0.66-0.73)$. The optimal threshold of this scoring system was set at 3 . Using this threshold, the prognostic accuracy was $91.0 \%$ (90.5-0.92.7), the positive predictive value was $22.0 \%(17.3-27.3)$ and the negative predictive value was $88.7 \%(87.4-89.4)$.

\section{Development of the decision tree}

The CHAID analysis provided a very simple algorithm. In the decision tree, the most powerful discriminator (splitter) was the PS; three subsets of patients were discriminated with increasing risk of early death: patients with $\mathrm{PS}=0$ (early death rate: $3.3 \%$ ), patients with $\mathrm{PS}=1$ (early death rate: $9.4 \%$ ) and patients with PS $\geqslant 2$ (early death rate: $25.5 \%$ ). There was no discriminator able to split the two first categories of patients. In the development data set, among patients with PS $\geqslant 2$, the histological grade was able to individualise two subsets of patients; when the grade was 3, the rate of early was $36.3 \%$ and in the other situations, the rate of early death was $19.5 \%$ (Figure 1).The area under the receiver operator curve was $0.67(0.64-0.71)$. The optimal classification was based on the separation of patients with PS $=(0-1)$ from other patients (Table 4). Using this classification, the prognostic accuracy was $86.2 \%(84.5-87.4)$, the positive predictive value was $25.3 \%$ (20.4-30.1) and the negative predictive value was $93.3 \%$ (92.0-94.6).

\section{Validation and head-to-head comparison of both models}

Both models were applied to the FSG cohort. The scoring system was applicable to 249 out of 404 patients $(61.6 \%)$. In this cohort, the area under receiver operator curve was $0.68(0.52-0.83)$. In this validation cohort, the prognostic accuracy of this scoring system, with a threshold set at 3, was $67.7 \%$. The CHAID algorithm was applicable to 347 out of 404 patients (85.9\%). Among patients with PS $\geqslant 2$, the rates of early death were similar whatever the histological grade. In this cohort, the area under receiver operator curve was $0.72(0.58-0.86)$. In this validation cohort, the prognostic accuracy of the CHAID algorithm was $89.0 \%$ $(86.5-93.5)$. In the development cohort, the prognostic accuracy of the CHAID algorithm was superior to the one of the scoring.

Because PS appears as the most important PF in both models, we evaluated the accuracy of PS as a PF for early death (see Figure 2). In the validation cohort, the area under the receiver operator curve of PS was similar to both other models: $0.72(0.58-0.86)$.

\section{DISCUSSION}

In both cohorts consisting of patients who were treated in the context of clinical trials with clear predefined eligibility criteria, the rates of early death were relatively low ( 8.6 and $4.5 \%)$. The rate of early death was significantly lower in the most recent trials (the French Sarcoma Group ones) that explored the role of polychemotherapy (MAID regimen) and the role of intensive chemotherapy. Hence, it is not surprising that the rate of early death was lower in trials with more stringent eligibility criteria. We have observed that the rate of early death in this population is 
Table 2 Risk factors for early death (development data set)

\begin{tabular}{|c|c|c|c|c|c|c|}
\hline Parameters & \multicolumn{3}{|c|}{ Univariate analysis } & \multicolumn{3}{|c|}{ Multivariate analysis } \\
\hline $40-49$ vs $<40$ & 1.32 & $0.87-2.00$ & 0.1816 & & & \\
\hline $50-59$ vs $<40$ & 1.41 & $0.95-2.08$ & 0.8450 & & & \\
\hline$\geqslant 60$ vs $<40$ & 1.77 & $1.21-4.6 \mid$ & 0.0030 & & & \\
\hline Gender: female vs male & 1.04 & $0.80-1.35$ & 0.7586 & & & \\
\hline I vs 0 & 3.04 & $2.11-4.36$ & $<.0001$ & 3.83 & $2.06-7.12$ & $<.0001$ \\
\hline $2-3$ vs 0 & 10.00 & $6.62-14.82$ & $<.0001$ & 12.00 & $5.53-26.06$ & $<.0001$ \\
\hline \multicolumn{7}{|l|}{ Interval $^{\mathrm{a}}$} \\
\hline Q2 vs Q1 & 0.80 & $0.55-1.17$ & 0.2618 & & & \\
\hline Q3 vs QI & 0.87 & $0.63-1.20$ & 0.4528 & & & \\
\hline Q4 vs QI & 0.41 & $0.27-0.61$ & $<.0001$ & & & \\
\hline \multicolumn{7}{|l|}{ Histological subtype } \\
\hline Angio vs leiomyo & 0.94 & $0.36-2.44$ & 0.899 & & & \\
\hline Syno vs leiomyo & 0.23 & $0.08-0.65$ & 0.005 & & & \\
\hline MPNST vs leiomyo & 0.48 & $0.21-1.07$ & 0.074 & & & \\
\hline Rhabdo vs leiomyo & 0.95 & $0.59-1.15$ & 0.818 & & & \\
\hline Unclassified vs leiomyo & 1.20 & $0.65-2.21$ & 0.558 & & & \\
\hline Other vs leiomyo & 0.91 & $0.40-2.06$ & 0.826 & & & \\
\hline \multicolumn{7}{|l|}{ Grade } \\
\hline$\|$ vs & 1.39 & $0.77-2.95$ & 0.2749 & & & \\
\hline||$|v|$ & 1.99 & $1.13-3.49$ & 0.0164 & & & \\
\hline \multicolumn{7}{|l|}{ Primary site } \\
\hline Head/neck vs limb & 1.88 & $0.88-4.00$ & 0.1029 & & & \\
\hline
\end{tabular}

Abbreviations: $\mathrm{Cl}=$ confidence interval; $\mathrm{RR}=$ relative risk; $\mathrm{MHF}=$ malignant histiocytofibroma; $M P N S T=$ malignant peripheral nerve sheath tumour; met. $=$ metastasis. ${ }^{\mathrm{a}} \mathrm{Q}$ ।: $0-60$ days; $\mathrm{Q} 2: 6$ I - 180 days; Q3: |8| -540 days; and Q4: >540 days.

Table 3 Early death rates according to the score and score accuracy in both cohorts

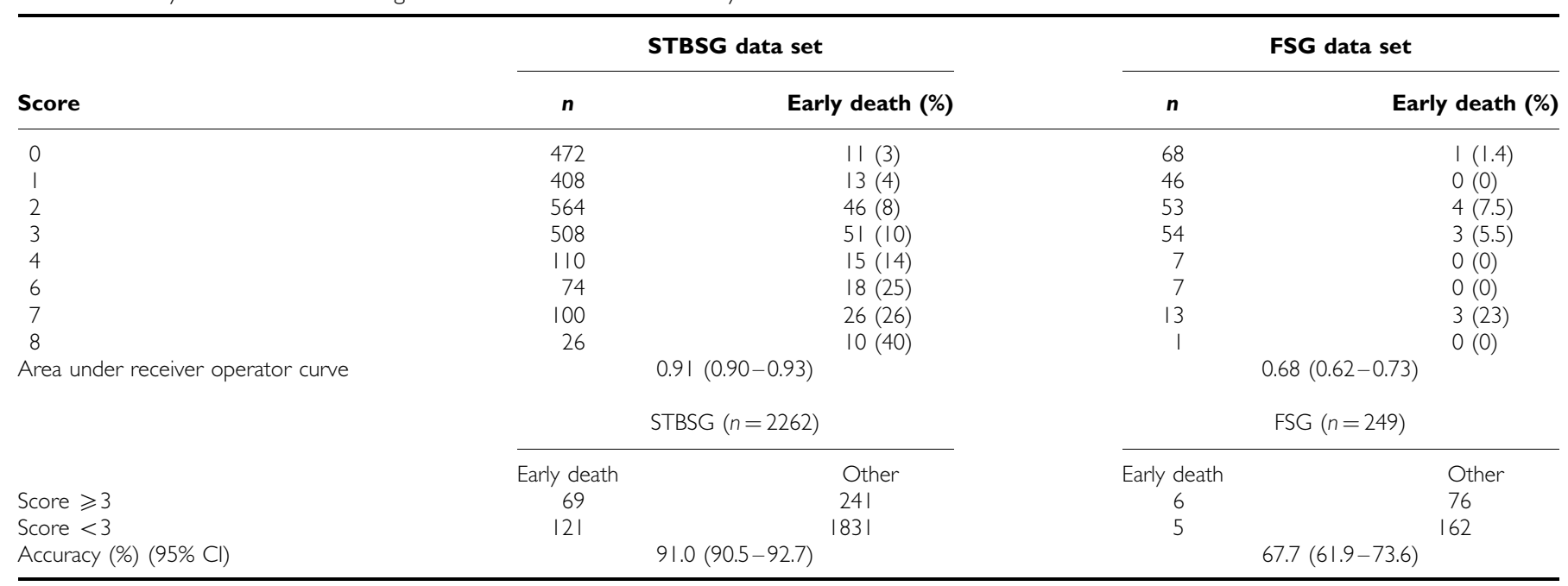

Abbreviations: STBSG = Soft Tissue and Bone Sarcoma Group; FSG = French Sarcoma Group; $\mathrm{Cl}=$ confidence interval. 

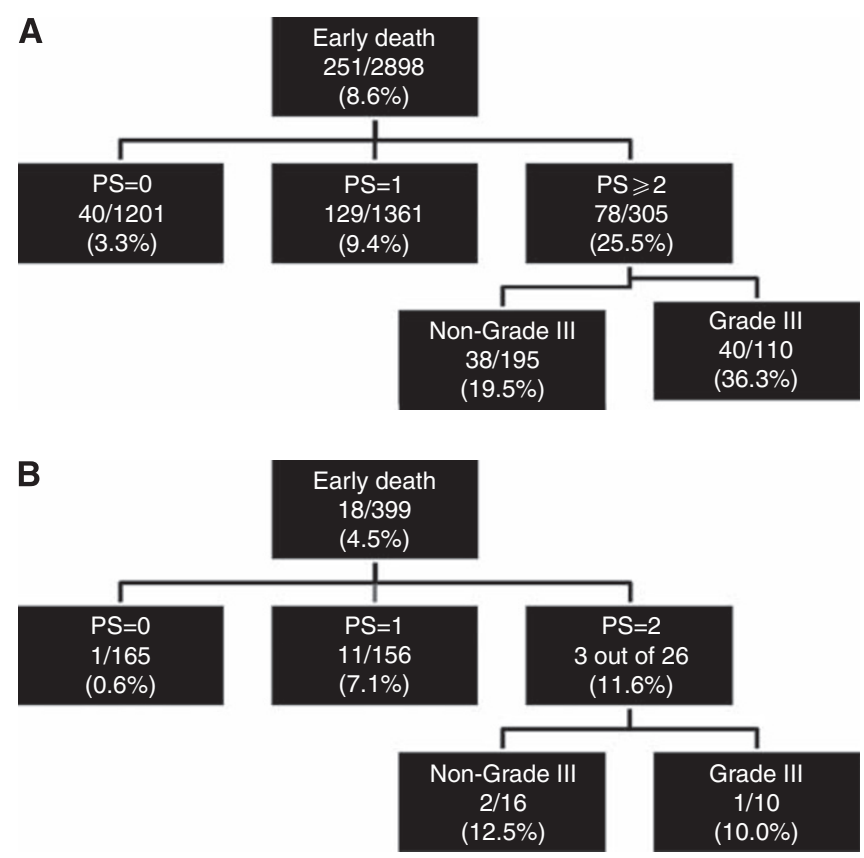

Figure I CHAID algorithms. (A) STBSG data set and (B) FSG data set.

Table 4 Early death rate according to probability tree analysis and algorithm accuracy in both cohorts

\begin{tabular}{|c|c|c|c|c|}
\hline \multirow{2}{*}{$\begin{array}{l}\text { Groups } \\
P S=0 \\
P S=1 \\
P S \geqslant 2 \text { and non-grade III } \\
P S \geqslant 2 \text { and grade III } \\
\text { Area under receiver } \\
\text { operator curve }\end{array}$} & \multicolumn{2}{|c|}{ STBSG } & \multicolumn{2}{|c|}{ FSG } \\
\hline & $\begin{array}{c}120 \mid \\
136 \mid \\
195 \\
110 \\
0.86\end{array}$ & $\begin{aligned} & 40(3.3) \\
& 129(9.4) \\
& 38(13.9) \\
& 40(36.4) \\
&84-0.87)\end{aligned}$ & $\begin{array}{l}165 \\
156 \\
16 \\
10 \\
0.89(C\end{array}$ & $\begin{aligned} \mid & (0.6) \\
\text { II } & (7.1) \\
2 & (12.5) \\
\text { I } & (10.0) \\
36- & 0.93)\end{aligned}$ \\
\hline & \multicolumn{2}{|c|}{ STBSG $(n=2867)$} & \multicolumn{2}{|c|}{ FSG $(n=347)$} \\
\hline $\begin{array}{l}P S \geqslant 2 \\
P S=(0-1) \\
\text { Accuracy }(\%)(95 \% \mathrm{Cl})\end{array}$ & $\begin{array}{c}\text { Early death } \\
78 \\
169 \\
86.2\end{array}$ & $\begin{array}{c}\text { Other } \\
227 \\
2393 \\
5-87.4)\end{array}$ & $\begin{array}{c}\text { Early death } \\
3 \\
12 \\
89.0(86\end{array}$ & $\begin{array}{c}\text { Other } \\
23 \\
309 \\
-93.5)\end{array}$ \\
\hline
\end{tabular}

Abbreviations: STBSG = Soft Tissue and Bone Sarcoma Group; FSG = French Sarcoma Group; $\mathrm{Cl}=$ confidence interval; $\mathrm{PS}=$ performance status.

lower than the reported one among patients entering in phase 1 trials $(\sim 16 \%)$ or in patients with carcinoma of unknown primary (30\%) (Geraci et al, 2006; Kelly et al, 2007; Arkenau et al, 2008; Penel et al, 2008, 2009; Ferté et al, 2010). The present analysis shows that PS is the most powerful PF for early death among patients with advanced STS treated with first-line systemic therapy. Using two complementary approaches, we developed and validated two prognostic models, which were however essentially based on the assessment of PS. The scoring system was more complex, incorporating three parameters, and was therefore available in a more limited part of the study population. The CHAID algorithm was based on twp variables (PS and histological grade) and was available in a larger proportion of patients. The implementation of the CHAID algorithm to the validation data set had showed that the second splitter (histological grade) did not improve the discrimination obtained with the first splitter (PS). Lastly, the prognostic performance of PS alone was as good as both other more sophisticated models (Figure 2).
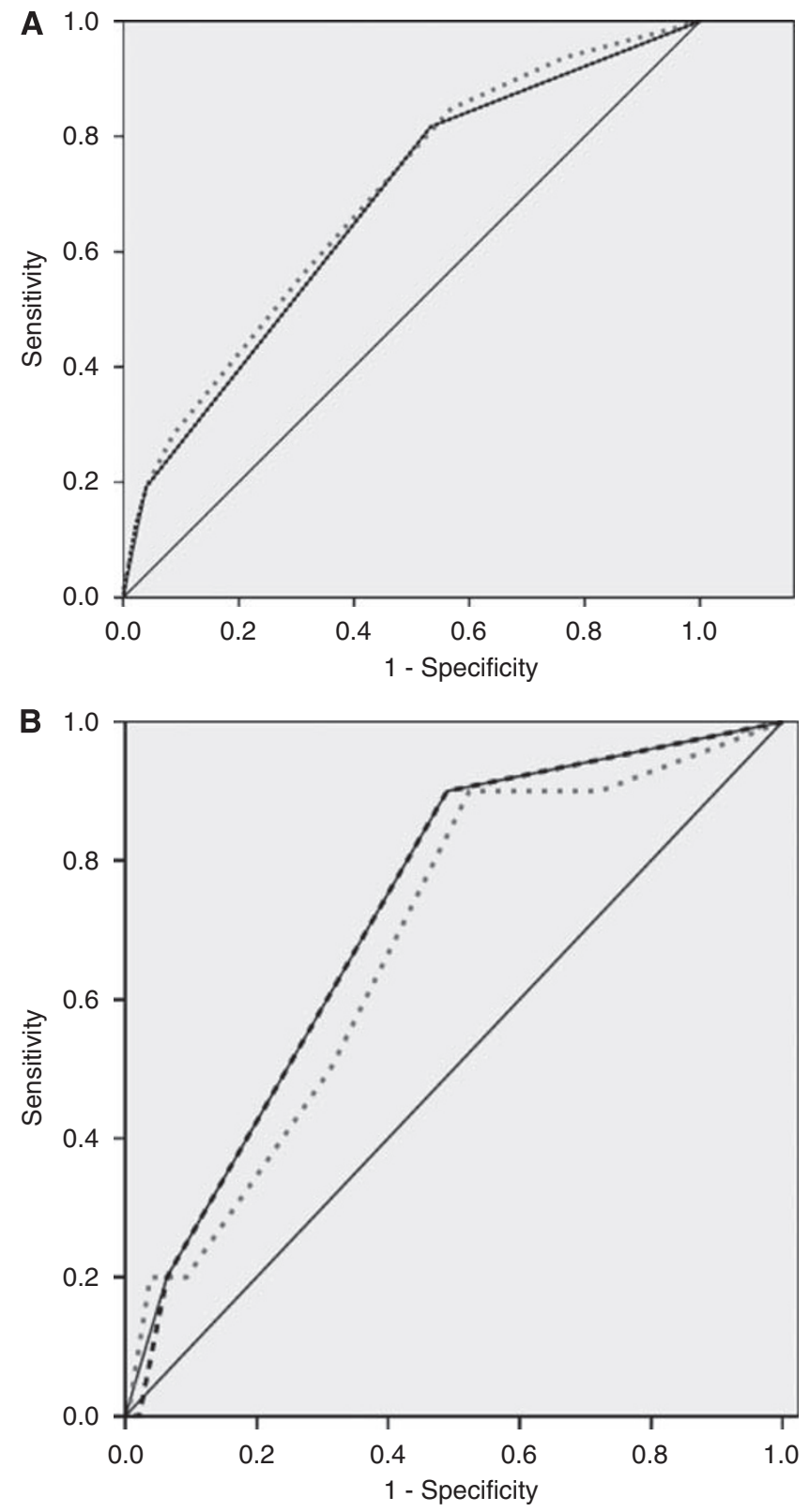

Figure 2 Area under receiver operator curves. (A) STBSG database. Grey dotted line: logistic regression-based scoring; black dotted line: $\chi^{2}$ interaction detection algorithm; black line: performance status alone as prognostic model (this line completely covers the CHAID algorithm line). (B) FSG database. Grey dotted line: logistic regression-based scoring; black dotted line: $\chi^{2}$ interaction detection algorithm; black line: performance status alone as prognostic model (this line completely covers the CHAID algorithm line).

The list of factors associated with early death identified in the present study is not surprising, and most of the identified factors have previously been revealed in other advanced STS databases as being related to outcome. The impact of presence of extrapulmonary and especially liver metastasis had been mentioned as a PF for OS in non-pretreated patients (Karavasilis et al, 2008; RayCoquard et al, 2009). Grade has also been identified as a PF for OS in non-pretreated patients (Antman et al, 1993). The time interval since the initial diagnosis of STS has been identified as a PF for OS in non-pretreated patients by Maurel et al (2009). Performance status appeared as a PF for OS in most studies (Borden et al, 1987; Karavasilis et al, 2008; Maurel et al, 2009; Ray-Coquard et al, 2009). 
The database used for the development of these predictive models for early death had previously been used for analysis of other PFs. Van Glabbeke et al (1999) found that the following factors were associated with OS in patients who received doxorubicin: PS ( $\mathrm{HR}=1.51, P<0.0001)$, liver metastasis $(\mathrm{HR}=1.46, P<0.0001)$, histological grade $(\mathrm{HR}=1.24, P=0.0002)$, time since initial diagnosis $\quad(\mathrm{HR}=0.92, \quad P=0.0004)$ and age $\quad(\mathrm{HR}=1.10$, $P=0.0045)$. In the same study, the following parameters were associated with objective response: liver metastasis $(\mathrm{OR}=0.38$, $P<0.0001)$, age $(\mathrm{OR}=0.83, P=0.0024)$ and histological grade $(\mathrm{OR}=1.35, P=0.051)$. Blay et al (2003) identified the following parameters as factors associated with long-term survival: PS $(\mathrm{OR}=2.02, P=0.0235)$, grade $(\mathrm{OR}=2.18, P=0.0009)$, female $(\mathrm{OR}=0.43, P=0.0291)$ and complete response obtained after first-line treatment $(\mathrm{OR}=0.11, P=0.0001)$. The originality of this work is that the relative weight of each PF and its interaction were studied in a very large data set using two complementary approaches, and the identified factors were validated in an independent cohort. At the end, the prognostic value of PS outweighs all other clinical parameters.

The limitations of this study are related to its retrospective nature. For example, grade scoring and pathological classification change during the study period. The prognostic value of grade scoring is not established for some particular histological subtypes (such as clear cell sarcoma, epithelioid sarcoma, angiosarcoma and so on). Moreover, the parameters used herein are the basic clinical variables. For other tumour types, more elaborate and sophisticated scores have been published, which integrate other parameters such as lymphocyte count, LDH level or albumin (Geraci et al, 2006; Kelly et al, 2007; Arkenau et al, 2008; Penel et al, 2008, 2009). These parameters were not available in a sufficiently large section of the STBSG cohorts and could not be explored in the present study. The additional value of these biological parameters should be evaluated. Furthermore, one could argue that the development of prognostic model for early death might be more relevant in patients failing first-line chemotherapy and candidates for second-line treatment. We plan this second analysis. Moreover, we ignore the precise cause of the death in both databases, especially the incidence of toxic death $v s$ death caused by progressive disease.

Despite its subjective nature, estimation of general condition by PS remains one of the most powerful PF in advanced/metastatic STS patients. Nevertheless, PS is not suitable for disabled and/or patients who suffer with persistent pain, for example, patients treated with previous mutilating surgical procedure. There are several scales available for scoring PS: the WHO-PS scale, the ECOG-PS scale or the Karnofsky PS scale. These different scales can generate discrepancies for evaluation of PS. It is well known that physicians overestimate both PS and life expectancy (Parkes, 1972; Evans and McCarthy, 1985; Christakis and Lemont, 2000; Ando et al, 2001). Ando et al (2001) had demonstrated that nurses and patients themselves estimate more accurately the actual PS than physicians.

Nevertheless, regarding its prognostic value, this variable has to be taken into account in future clinical trials, for example, as stratification factors at inclusion in randomised trials. For clinical decision making, both models developed are far from ideal. The probability of early death for a patient with PS $\geqslant 2$ is $\sim 11-24 \%$ compared with $0-3 \%$ for those with $\mathrm{PS}=0$ (Figure 1 ). In everyday practice, this does not imply that all patients with PS $\geqslant 2$ should be denied palliative chemotherapy per se, but the high risk of an early death and the potential lack of benefit from treatment should be discussed with the patient before a decision is made to proceed with chemotherapy. Further studies are warranted to develop and validate more accurate prognostic models, if possible based on objectively measurable variables (such as biological parameters) and excluding PS.

\section{REFERENCES}

Ambalavanan N, Carlo WA, Shankara S, Bann CM, Emrich SL, Higgins RD, Tyson JE, O'Shea TM, Laptook AR, Ehrenkranz RA, Donovan EF, Walsh MC, Goldberg RN, Das A, National Institute of Child Health and Human Development Neonatal Research Network (2006) Predicting outcomes of neonates diagnosed with hypoxemic-ischemic encephalopathy. Pediatrics 118: $2084-2093$

Antman K, Crowley J, Balcerzak SP, Rivkin SE, Weiss GR, Elias A, Natale RB, Cooper RM, Barlogie B, Trump DL (1993) An intergroup phase III randomized study of doxorubicin and dacarbazine with or without ifosfamide and mesna in advanced soft tissue and bone sarcomas. J Clin Oncol 11: 1276-1285

Ando M, Ando Y, Hasegawa Y, Shimokata K, Minami H, Wakai K, Ohno Y, Sakai S (2001) Prognostic value of performance status assessed by patients themselves, nurses and oncologists in advanced non-small cell lung cancer. Br J Cancer 85: 1634-1639

Arkenau HT, Barriuso J, Olmos D, Ang JE, de Bono J, Judson I, Kaye S (2009) Prospective validation of a prognostic score to improve patient selection for oncology phase I trials. J Clin Oncol 27: $2692-2696$

Arkenau HT, Olmos D, Ang JE, de Bono J, Judson I, Kaye S (2008) Clinical outcome and prognosis factors for patients treated within the context of a phase I study: the Royal Marsden Hospital experience. Br J Cancer 98: $1029-1033$

Barton CA, McKenzie DP, Walters EH, Abramson MJ, Victorian Asthma Mortality Study Group (2005) Interactions between psychosocial problems and management of asthma: who is at risk of dying? J Asthma 42: $249-256$

Benjamin RS (1987) Grade 3 nausea, vomiting, and myelosuppression or progressive sarcoma? J Clin Oncol 5: 833-835

Blay JY, Van Glabbeke M, Verweij J, Van Oosterom AT, Le Cense A, Oosterhuis JW, Judson I, Nielsen OS (2003) Advanced soft-tissue sarcoma: a disease that is potentially curable for a subset of patients treated with chemotherapy. Eur J Cancer 39: 64-69
Borden EC, Amato DA, Rosenbaum C, Enterline HT, Shiraki MJ, Creech RH, Lerner HJ, Carbone PP (1987) Randomized comparison of three adriamycin regimens for metastatic soft tissue sarcomas. J Clin Oncol 5: $840-850$

Bui BN, Chevreau C, Penel N, Bay JO, Coindre JM, Mathoulin-Pelissier S, Ray-Coquard I, Italiano A, Genéve J, Blay JY, The PALSAR 02 Clinical Trial Group (2009) Consolidation with chemotherapy intensification in advanced, metastatic soft tissue sarcoma (STS) of adults. A FNCLCCFrench Sarcoma Group phase II multicentric study. J Clin Oncol 27: Abstract 10505

Chan F, Cheing G, Chan JYC, Rosenthal DA, Chronister J (2006) Predicting employment outcomes of rehabilitation clients with orthopedic disabilities: a CHAID analysis. Disabil Rehabil 28: 257-270

Christakis NA, Lemont EB (2000) Extent and determinants of error in doctors prognoses in terminally ill patients: prospective cohort study. BMJ 320: $469-472$

Clark MA, Fischer C, Judson I, Thomas JM (2005) Soft-tissue sarcomas in adults. $N$ Engl J Med 353: 701-711

Clément-Duchêne C, Carnin C, Guillemin F, Martinet Y (2010) How accurate are physicians in the prediction of patient survival in advanced lung cancers? Oncologist 15: 782-789

Courville XF, Koval KJ, Carney BT, Spratt KF (2009) Early prediction of posttraumatic in-hospital mortality in pediatric patients. $J$ Pediatr Orthop 29: 439-444

Evans C, McCarthy M (1985) Prognostic uncertainty in terminal care: can the Karnofsky index help? Lancet 1: 1204-1206

Fayette J, Penel N, Chevreau C, Blay JY, Cupissol D, Thyss A, Guillemet C, Rios M, Rolland F, Fargeot P, Bay JO, Mathoulin-Pelissier S, Coindre JM, Bui-Nguyen B (2009) Phase III trial of standard versus dose-intensified doxorubicin, ifosfamide and dacarbazine (MAID) in the first-line treatment of metastatic and locally advanced soft tissue sarcoma. Invest New Drugs 27: 482-489 
Ferté C, Penel N, Bonneterre J, Adenis A (2010) Individual life-expectancy estimation using validated prognostic scores for patients cancer of unknown primary. Oncology 78: 87-93

Geraci JM, Tsang W, Valdres RV, Escalante CP (2006) Progressive disease in patients with cancer presenting to an emergency room with acute symptoms predicts short-term mortality. Supp Care Cancer 14: 1038-1045

Karavasilis V, Seddon BM, Ashley S, Al-Muderis O, Fischer C, Judson I (2008) Significant clinical benefit of first-line palliative chemotherapy in advanced soft-tissue sarcoma. Retrospective analysis and identification of prognostic factors in 488 patients. Cancer 112: 1585-1591

Kelly L, White S, Stone PC (2007) The B12/CRP index as a simple prognostic indicator in patients with advanced cancer: a confirmatory study. Ann Oncol 18: 1395-1399

Linden A (2006) Measuring diagnostic and predictive accuracy in disease management: an introduction to receiver operating characteristics (ROC) analysis. J Eval Clin Pract 12: $132-139$

Maltoni M, Nanni O, Innocenti MP, Maltoni M, Nanni O, Derni S, Innocenti MP, Fabbri L, Riva N, Maltoni R, Amadori D (1994) Clinical prediction of survival is more accurate than the Karnofsky performance status in estimating life span of terminally ill cancer patients. Eur J Cancer 30A: $764-766$

Maurel J, López-Pousa A, de Las Peñas R, Fra J, Martín J, Cruz J, Casado A, Poveda A, Martínez-Trufero J, Balañá C, Gómez MA, Cubedo R, Gallego O, Rubio-Viqueira B, Rubió J, Andrés R, Sevilla I, de la Cruz JJ, Del Muro XG, Buesa JM (2009) Efficacy of sequential high-dose doxorubicin and ifosfamide compared with standard-dose doxorubicin in patients with advanced soft tissue sarcoma: an open-label randomized phase II study of the Spanish Group for Research on Sarcoma. J Clin Oncol 27: $1893-1898$

Melchior LA, Huba GJ, Gallagher T, Jean-Louis E, McDonald SS, Smereck GA, German VF, Brown VB, Panter AT (2001) Unmet needs in groups of traditionally underserved individuals with HIV/AIDS: empirical models. Home Health Care Serv Q 19: 29-51
Parkes CM (1972) Accuracy of prediction of survival in later stages of cancer. Br Med J 2: 29-31

Penel N, Vanseymortier M, Bonneterre ME, Clisant S, Dansin E, Vendel Y, Beuscart R, Bonneterre J (2008) Prognostic factors among cancer patients with good performance status screened for phase I trials. Invest New Drugs 26: $53-58$

Penel N, Négrier S, Ray-Coquard I, Ferté C, Devos P, Hollebecque A Sawyer MB, Adenis A, Séve P (2009) Development and validation of a bedside score to predict early death in cancer of unknown primary patients. PLOS One 4: e6483

Ray-Coquard I, Cropet C, Van Glabbeke M, Sebban C, Le Cesne A, Judson I, Tredan O, Verweij J, Biron P, Labidi I, Guastalla JP, Bachelot T, Perol D, Chabaud S, Hogendoorn PC, Cassier P, Dufresne A, Blay JY, European Organization for Research and Treatment of Cancer Soft Tissue and Bone Sarcoma Group (2009) Lymphopenia as a prognostic factor for overall survival in advanced carcinomas, sarcomas and lymphomas. Cancer Res 69: 5383 - 5391

Sessa C, Roggero E, Pampallona S, Regazzoni S, Ghielmini M, Lang M, Marx B, Neuenschwander H, Pagani O, Vasilievic V, Cavalli F (1996) The 3 last months of life cancer patients: medical aspects and role of homecare services in southern Switzerland. Support Care Cancer 4: 180-183

Simon R, Altman DG (1994) Statistical aspects of prognostic factor studies in oncology. $\mathrm{Br}$ J Cancer 69: 979-985

Sleijfer S, Seynaeve C, Verweij J (2005) Using single-agent therapy in adult patients with advanced soft tissue sarcoma can still be considered standard care. Oncologist 10: 833-841

Van Glabbeke M, van Oosterom AT, Oosterhuis JW, Mouridsen H, Crowther D, Somers R, Verweij J, Santoro A, Buesa J, Tursz T (1999) Prognostic factors for the outcome of chemotherapy in advanced soft tissue sarcoma: an analysis of 2185 patients treated with anthracyclinecontaining first-line regimens-a European Organization for Research and Treatment of Cancer Soft Tissue and Bone Sarcoma Group Study. J Clin Oncol 17: $150-157$ 